Journal of Research in Interprofessional

Practice and

Education

Vol. 6.2

2016

\title{
Promoting Interprofessional Collaboration: A Pilot Project Using Simulation in the Virtual World of Second Life
}

\author{
Deborah Lee Davis RM, PhD \\ ACT Health \& University of Canberra \\ Gylo Hercelinskyj, RN, PhD \\ Australian Catholic University \\ Lynette M. Jackson, B.HScN \\ Canberra Institute of Technology
}

\begin{abstract}
Background: Contemporary health services increasingly call for teamwork and interprofessional collaboration, though undergraduate curricula provide few opportunities for students to develop the necessary skills. This article presents the results of an innovative pilot project focusing on providing an interprofessional clinical learning experience for students using the virtual world of Second Life.

Methods and Findings: A pilot project was implemented and tested on a small group of students studying at two institutions in four healthcare programs. Qualitative descriptive methods were employed to analyze semi-structured interview transcripts. The evaluation revealed that participants were easily able to manage the technologies associated with Second Life and the learning and teaching strategies were engaging and useful. While the project provided students with an opportunity to learn more about the role of other health professionals and their contribution to patient care, it will require some development before it achieves in full the aim to promote interprofessional collaboration.

Conclusions: Simulation in virtual worlds such as Second Life offers promise in the area of interprofessional education.
\end{abstract}

Keywords: Simulation; Collaboration

\section{Introduction}

Regardless of the health profession, there is an urgent need to prepare students for

Journal of Research in Interprofessional Practice and Education (JRIPE)

Vol. 6.2

(C) 2016

Corresponding author: Deborah Lee Davis.

Email: Deborah.davis

@canberra.edu.au the complexities of working in today's multifaceted healthcare system [1]. Increasingly crowded curricula and limited clinical learning opportunities mean that we not only need to select and deliver appropriate content in a finite timeframe but also provide students with the opportunity to experience their discipline within a realistic context of clinical practice. Simulation is increasingly used in the education of health professionals as it provides students with a safe environment in which to develop their knowledge, critical thinking ability, and confidence [2]. While simulated teaching and learning opportunities using manikins are commonplace, virtual 
2

Collaboration in the Virtual World of Second Life

Davis, Hercelinskyj, \& Jackson

Journal of Research in Interprofessional Practice and Education

Vol. 6.2

2016 environments also offer opportunities-though these are less well explored in the healthcare context.

Contemporary healthcare services are also increasingly calling for teamwork and cooperation within an interprofessional collaborative framework [3,4]. The World Health Organization promotes interprofessional education as "a necessary step in preparing a 'collaborative practice-ready' health workforce that is better prepared to respond to local health needs" [5, p. 7], and internationally, governments, regulators, and educators are recognizing the need for interprofessional education and collaboration [6,7]. In this article, the term "interprofessional collaboration" refers to "a partnership between a team of health providers and a client in a participatory, collaborative and coordinated approach to shared decision-making around health and social issues" [7] and "interprofessional education" (IPE) as "occasions when two or more professions learn with, from and about each other to improve collaboration and the quality of care" $[6$, n.p.]

Interprofessional collaboration is seen to provide the best opportunity for consumers to receive care influenced by a range of professional understandings. The aim is to improve the quality and diversity of care options offered [8,9], with effective communication between healthcare professionals viewed as one of the cornerstones of high-quality patient care. In Australia, national policy statements around such areas as workforce planning and development, mental health, and primary health all promote the need for interprofessional collaboration to deal with and respond to the increasingly complex needs of patients and their families [1]. To meet these government policy directions and provide students with the capacity to deliver healthcare within an interprofessional collaborative framework, it is crucial that students be taught accordingly [10]. The challenge lies in finding space in already-crowded discipline-specific curricula in order to provide interprofessional learning opportunities (interprofessional education).

This article presents a pilot study with two main foci: the development of a simulated clinical practice opportunity using web-based platforms (the virtual world of Second Life and Wikispaces), and embedded within this, an interprofessional education strategy. The learning and teaching strategy was aimed at providing for the discipline-specific needs of a variety of healthcare students from two different institutions, while also focusing on the development of skills related to interprofessional collaboration. Interprofessional education, and the novel virtual environment in which it took place in this pilot, is considered to offer rich opportunities for the promotion of interprofessional collaboration. This is a small-scale project that set out to examine if the learning and teaching strategy as we envisaged it was possible, and if those who experienced it considered it useful. The description and evaluation of this project offers lessons for academics and educators in the healthcare professions concerning the concept, the considerations, the feasibility, and perhaps to a lesser extent, the usefulness of using web-based technologies such as virtual worlds in preparing healthcare students to work in an interprofessional collaborative context. This represents a tentative first step in this direction for our faculty and will inform future initiatives. 
3

Collaboration in the Virtual World of Second Life

Davis, Hercelinskyj, \& Jackson

Journal of Research in Interprofessional Practice and Education

Vol. 6.2

2016

\section{Background}

Interprofessional education is considered a form of collaborative and interactive learning with, from, and about other disciplines for the purpose of improving teamwork and consumer outcomes [11]. Interprofessional education is seen as the means by which clinicians can develop the knowledge and skills to ensure that more effective and efficient service delivery-via a multidisciplinary team structure-can occur [12]. Some argue that interprofessional learning increases one's understanding of others' roles and scope of practice, as well as facilitating collaboration in practice [13] in a way that uniprofessional teaching and learning strategies cannot. Additionally, students who have the opportunity to work together closely and communicate frequently develop trust and mutual respect [14,15]. Ateah, Snow, Wener, MacDonald, Matge, Davis, Fricke, Ludwig, \& Anderson [16] for example, found that participants in Canada had more positive perceptions of other healthcare professionals following an interprofessional education session with participants from four faculty: dentistry, medicine, nursing, and pharmacy. Others have found that interprofessional education in the clinical setting can improve team performance, particularly in acute care settings $[17,18]$. Critics of IPE point to the lack of theoretical development underpinning IPE initiatives, the lack of valid and reliable learning outcomes relevant to IPE, and the failure of IPE (and research focusing on IPE) to address wider concerns of professional identity and power relations. Concerns have also been raised about the potential lack of congruence between what is taught in the education environment and what the healthcare student experiences in the clinical setting [19].

A cross-sectional survey of select Australian and New Zealand academic institutions [20] (those offering nursing, medical, and pharmacy programs) found that a large proportion of institutions reported incorporating interprofessional education in their programs. When examined more closely however, most of the IPE strategies cited failed to meet the accepted definition of IPE according to the Centre for the Advancement of Interprofessional Education [6]. These strategies included, for example, lectures given to an audience studying a variety of healthcare professions. These strategies do not provide for the sustained interaction that facilitates communication, shared understanding, the development of relationships, and thus interprofessional collaboration.

While many agree that IPE is beneficial, a host of barriers have been identified that tend to encourage a "silo" approach to the education of healthcare professionals. Barriers include difficulties with timetabling [21], staff and student attitudes [22], lack of resources, and funding support [20]. In addition, students may not have opportunities to see interprofessional collaboration at work if the clinical areas in which they are placed do not demonstrate or make overt the interprofessional nature of the healthcare provided. Simulated clinical experiences that demand an interprofessional collaborative approach is a teaching and learning strategy that offers promise. While others have used simulated clinical experiences in education to foster interprofessional collaboration [23], these experiences have focused on acute situations in emergency room and intensive care settings. We are not aware of any other simulations that aim to develop interprofessional collaboration in the non-acute healthcare context. 
4

Collaboration in the Virtual World of Second Life

Davis, Hercelinskyj, \& Jackson

Journal of Research in Interprofessional Practice and Education

Vol. 6.2

2016
Authentic learning opportunities that replicate the reality of clinical practice are considered vital for promoting role socialization and a sense of professional identity for students [24]. However, increasingly limited clinical learning opportunities restrict student contact with peers and other healthcare colleagues and can impede their integration into the interprofessional context of practice. In healthcare, simulated learning experiences are those that imitate real-world clinical situations or settings. A well-designed simulation closely replicates the actual clinical environment or experience and can contribute to authentic learning. Simulations may include the use of technologically advanced equipment, such as computerized manikins, or lowtechnology strategies such as role-play $[25,26]$. A key feature of simulation for Heinrichs, Youngblood, Harter, \& Dev [17] is a realistic environment: "The central strength of simulation is 'environments' realistic enough to allow trainees so suspend disbelief" (p. 163). Three-dimensional virtual worlds such as Second Life also offer an environment for simulated clinical experiences and have been shown to provide an engaging, immersive learning experience [27] and an environment that allows for a sense of presence or "really being in the situation."

Simulated environments are controlled settings [28] that have a number of advantages for student learning, including the opportunity to practice in a safe environment that presents no direct risk to patients [29], develop clinical skills through repetitive practice [30], develop teamwork skills [31], and experience settings or scenarios that may not be available in real life [32]. While virtual worlds have been used for teaching and learning in healthcare education [33], few have explored the opportunities this media offers for interprofessional education or the development of knowledge, skills, and attitudes necessary for interprofessional collaboration. It is here that this article makes a contribution by describing and reporting on the evaluation of a pilot project aimed at promoting interprofessional collaboration in a non-acute situation, using simulation in the virtual world of Second Life.

\section{Project description}

A steering committee was established to guide the development of the project. The committee was constituted by members from two institutions, Canberra Institute of Technology (Institution A) and University of Canberra (Institution B), representing programs aimed at students studying enrolled nursing (Institution A), registered nursing, dietetics and nutrition, and pharmacy (Institution B). Within the broad remit of the project, "to provide a platform to allow undergraduate healthcare students to participate in an environment that is authentic in nature and encourages the use of interprofessional communication," the committee was tasked with developing learning and teaching opportunities that reflected discipline-specific needs and the overarching outcomes related to interprofessional learning. The following principles guided the development of the learning and teaching strategies. The teaching and learning activity:

- Facilitates collaboration between the professions represented;

- Ensures meaningful participation of each member of the student group; 
Collaboration in the Virtual World of Second Life

Davis, Hercelinskyj, \& Jackson

Journal of Research in Interprofessional Practice and Education

Vol. 6.2

2016

\section{Journal of Research in Interprofessional Practice and Education}

- Ensures that the scope of practice of each professional area is adequately acknowledged; and

- Provides each student with equal opportunity to demonstrate knowledge and skills within his or her identified scope of practice.

The steering committee agreed to develop a clinical scenario involving an elderly patient who required admission to an acute hospital following deterioration at home. The details of the scenario ensured that her condition would require the involvement of all professions participating in the project. It was agreed that individual students would review relevant clinical documentation for the patient and meet with the patient individually in the virtual environment for an interview and assessment. Once all students had interviewed the patient they would meet in the virtual environment to develop a collaborative care plan; one involving input from all the professions involved. The learning outcomes for the students included:

- Developing basic navigation, communication, and information sharing skills of relevance to the online virtual environment;

- Applying discipline-specific client assessment and care planning process to the health journey of the client (in the virtual environment); and

- Participating in an interprofessional team meeting, discussing and developing a collaborative plan for the client with input from other members of the healthcare team.

\section{Clinical information and the wiki}

To facilitate communication and to act as a repository for all information associated with the scenario, a wiki was established. Educators representing the various professions worked together and individually to elaborate the scenario and develop relevant clinical resources, including client history, progress notes, pathology and radiography results, images (for example photographs of sites prone to pressure injury), medication charts, assessments, and referral forms. The learning and teaching strategy required students to review the information provided on the wiki prior to meeting with the patient in the virtual hospital. The steering committee would have preferred that all information relating to the patient be available in the virtual world. This could be achieved by linking relevant documents or images to artefacts within the virtual hospital. However, the programming necessary to achieve this would have come at significant cost and this was beyond the budget of the project. The wiki was, therefore, a compromise, though it was felt that the process for students to engage in the scenario was more unwieldy than the committee would have liked. Once students had completed their assessment of the client in Second Life (described below) they were asked to complete a "position paper" identifying (based on the discipline-specific assessment) the priority needs for the client and providing the rationale for their judgment. This was to be uploaded to the wiki and made available to other interprofessional team members. 
6

Collaboration in the Virtual World of Second Life

Davis, Hercelinskyj, \& Jackson

Journal of Research in Interprofessional Practice and Education

Vol. 6.2

2016

\section{Avatars and the virtual hospital}

Institution A had an existing hospital built in Second Life and this was utilized for the project. A number of avatars were prepared for the project including "Eunice" (the patient), a dietician, a nurse, an enrolled nurse, and a pharmacist. All students participating in the project were provided with a face-to-face orientation to Second Life and the virtual hospital prior to engaging with the scenario. This consisted of a one and half hour computer laboratory session that aimed to provide students with the skills to log in to Second Life, locate the virtual hospital (ward and meeting room), navigate the environment, and communicate with others using text and voice. Students were provided with login details for the appropriate avatar, and a time to interview and assess "Eunice" was individually negotiated. "Eunice" was played by a variety of educators using the same backstory and clinical information developed by the steering committee to ensure consistency. As mentioned above, students were asked to access the relevant clinical information provided on the wiki in advance of meeting "Eunice" in the virtual setting, though most educators printed off the material and provided students with a hard copy package of information.

Once all students had interviewed "Eunice" (a process that occurred over approximately two weeks), a time was negotiated to hold an interprofessional meeting in the meeting room of the virtual hospital. An educator facilitated the meeting to guide the students through the process and ensure that all participants were given an opportunity to engage in the discussion and planning. It was expected that students had read each other's "position paper" on the wiki, and that they would discuss the clinical situation offering their discipline-specific perspective and then construct a cohesive plan of care that reflected the input of the team.

\section{Evaluation}

\section{Methods}

A qualitative descriptive methodology [34] was employed, with individual, semi-structured interviews utilized as the data collection method. This was deemed the most suitable method given the aims of the evaluation, which included describing the participant's experience of working with the technology, the relevance of the clinical scenario, and the contribution that the activity made to student learning, particularly in relation to interprofessional collaboration. A qualitative descriptive approach is not driven by a particular theoretical framework and aims for a low-inference analysis [34].

Interviews were conducted mostly face-to-face, with one conducted by telephone. The location of the face-to-face interviews was negotiated with participants and all occurred on campus in meeting rooms or staff offices and lasted between 30 to 45 minutes. Members of the steering committee conducted the evaluation, with those from Institution A interviewing participants from Institution B and vice versa. This was to ensure that participants did not feel coerced by ongoing relationships or unequal power relationships (between students and lecturers for example). We acknowledge that members of the steering group had an interest in the outcome of the evaluation, but engagement of more objective, external evaluators was beyond the limited budget of this project. In line with the aims of the evaluation, interview 
7

Collaboration in the Virtual World of Second Life

Davis, Hercelinskyj, \& Jackson
Journal of Research in Interprofessional Practice and Education

Vol. 6.2

2016 questions focused on the areas of technology, discipline-specific learning, and interprofessional collaboration. The lead questions were open and included, for example, "How was the experience for you?" then developed into more probing questions, such as, "So how was that useful to you?"

All interviews were audiotaped and transcribed verbatim. The first author led the analysis and proceeded using the aims of the evaluation as the coding framework. Interview transcripts were read and each unit of meaning (a sentence or group of sentences conveying a concept or message) was provided with a code. Data were examined for opposing positions, though in this small sample there was general agreement. The tentative findings were presented to the steering committee where they were discussed in full. No amendments resulted from these discussions and these findings were finalized.

\section{Ethics}

Ethics approval to conduct the evaluation was gained through the University of Canberra Human Research Ethics Committee. All participant information and consent forms stressed that participation was voluntary and that the decision to participate would in no way impact on student's grades or progress in their respective courses. Project team members not directly involved in teaching the student participants conducted all interviews.

\section{Sample and recruitment}

Lecturers teaching in relevant healthcare programs at Institution A and Institution B were first approached to identify whether the planned teaching and learning intervention would be suitable for their students and whether they would like to collaborate on the project. We approached lecturers teaching nursing, nutrition and dietetics, physiotherapy, pharmacy, and enrolled nursing programs. Medicine was not included, as it was not offered at these institutions. All except physiotherapy were able to collaborate and an expression of interest was then circulated to students in these programs to obtain a cohort willing to engage with the project. Due to resource limitations we were interested in testing the innovation with no more than two interprofessional teams (with five students each representing the participating professions). Participation in the project was an extracurricular activity and students were under no obligation to participate. Six students expressed an interest and formed the pilot group-one student of pharmacy, one of nursing, two of enrolled nursing, and two of nutrition and dietetics. This group thus represented a self-selected cohort. None of the students or staff members interviewed had any prior experience with virtual worlds. Following the conclusion of the pilot activity, students and staff who were involved were emailed and invited to participate in the evaluation of the project (eight in total including a lecturer in nursing and nutrition and dietetics). They were provided with a participant information sheet that explained all aspects of the evaluation. Once agreement to participate in the evaluation was given, participants were asked to sign a consent form. Three students (from nutrition and dietetics, enrolled nursing, and pharmacy) and two staff members (nursing and nutrition and dietetics) took part in the interviews. 
8

Collaboration in the Virtual World of Second Life

Davis, Hercelinskyj, \& Jackson
Journal of Research in Interprofessional Practice and Education

Vol. 6.2

2016

\section{Results}

Drawing on interview data, the findings of the evaluation have been grouped into three descriptive categories. These are: technology, discipline-specific skill development, and interprofessional collaboration.

\section{Immersive technology}

While none of the participants had engaged with virtual worlds previously, most were able to use the technology and navigate the scenario and virtual environment successfully. Participants highlighted the importance of the orientation:

I don't think it's a huge learning curve. Once you get that orientation you get a feel for what it's about. I guess with different ages, like the younger ones ... I am forty, the younger ones coming through at uni and [tech] ... it's not going to be a bother to them at all. I think just initially it's all new ... and yeah it's pretty easy to pick up given that orientation. (Student 1)

Unfortunately there was an ongoing problem with the use of the voice function in Second Life. For some students, this meant that they could not interview the patient or participate in the collaborative meeting using the voice features of Second Life. We attempted to ameliorate this situation with the use of a mobile phone, though this was a less than an ideal compromise. Despite this problem, participants found that the environment provided an immersive experience, with one student blurring the boundaries of the real and virtual commenting:

Oh it did, it was wonderful, it gave you that opportunity to be in a real life [clinical] setting and ask the questions that I would ask [of the patient]. (Student 3)

For one participant the immersive nature of the experience meant that she was able to relate to the "patient" to a greater extent and this provided her with "really good preparation for talking to real people." In comparing the experience of paperbased case studies with the Second Life scenario, one participant stressed the value of situating the case study within a clinical setting, albeit a virtual one:

[T] he room is set up as a ward room with all the beds in it and that sort of thing ... [it's] fantastic because it gets people used to not just what's on a piece of paper but their surroundings. (Student 2)

The resemblance of the Second Life environment to a real life hospital and the development of clinical records that resembled real life clinical records added to the authenticity of the experience, and participants valued this.

Yeah, it is exactly like you would have in the hospital, so it's nice to have that real life comparison to what you would have in a hospital; the admission sheet was familiar, the progress notes gave a lot of information as well. I found it really useful. (Student 1)

While there were some issues with the technology, participants found that they were able to master the necessary skills to engage with the teaching and learning 
Collaboration in the Virtual World of

Second Life

Davis, Hercelinskyj, \& Jackson
Journal of Research in Interprofessional Practice and Education

\section{Journal of Research in Interprofessional Practice and Education}

strategies relatively easily, and that the technology provided for an immersive experience that offered a richer experience than they would have had using other forms of case study.

\section{Knowledge and skill development}

Students studying in the various disciplines are exposed to a variety of real life clinical placements. The project provided students studying dietetics and nutrition with an opportunity to experience a clinical situation that was not available to them in real life clinical placements.

I guess [it was positive for the students to gain experience with] aged care and outpatients, so looking at things like fluid balance charts and medication charts, they don't do a whole lot of that. So I think it was a really good scenario to get them thinking about discharge planning that you don't really need to do as part of our placements. So it was a good introduction I guess to that real acute setting. (Staff member 1)

For other students the project provided them with an opportunity to practice clinical skills in settings in which they may already be familiar. Students participating in the evaluation found this experience relevant to their curriculum and useful preparation for real life clinical experiences.

Yeah I have done a lot of pracs [practical placements]. I have only admitted a couple of patients with supervision but that's what I found most useful was a bit of practice for admitting a patient and the type of questions you would ask. (Student 3)

In the virtual environment students had greater autonomy than they did in real life clinical placements, as this exchange demonstrates:

Student 2: I felt like not so much that I was in charge, but it gave me the opportunity to get my point of view across and I got to do some decision making as well.

Interviewer: And is that not an experience you have when you are on your placements?

Student 2: Not so much. Well we get to have a lot of input into the care plans but you are always sort of referring back to your preceptor to check if everything is right. It sort of made me feel a bit more like I was out there actually on my own and I was responsible for the patient sort of thing.

The student studying pharmacy (who was experienced in communicating with patients through previous employment in healthcare), found the care planning aspects of the project particularly useful. After interviewing the patient and prior to the collaborative meeting, she was prompted to investigate the key clinical issues that she identified with the patient during her interviews. 


\section{JRIPE}

10

Collaboration in the Virtual World of

Second Life

Davis, Hercelinskyj, \& Jackson
Journal of Research in Interprofessional Practice and Education

Vol. 6.2

2016

\section{Journal of Research in Interprofessional Practice and Education}

It was the scenario and the interview with the patient ... I went away and went, okay so these are the areas that she's having problems in. What is it we do in pharmacy to combat breakthrough pain and what do we use for constipation caused by the pain relief that they are getting and all that sort of thing? So yeah ... I had to go look at all the pharmacy side of things. (Student 1)

The project provided students with a variety of opportunities for consolidating their knowledge and developing skills relevant to their individual disciplines. In the safety of the virtual environment students experienced a greater sense of professional autonomy and accountability, as they were free to engage with the patient as they saw fit and to make clinical decisions while also feeling the weight of the responsibility that comes with this.

\section{Collaboration}

One of the key aims of the initiative was to facilitate interprofessional collaboration. Students interviewed the patient individually and then met with students from other disciplines to develop a collaborative care plan. For the lecturer in nutrition and dietetics, this was an aspect of the degree program that was lacking.

So it was a good introduction, I guess, to that real acute setting and I think the one thing they really lack on these placements is the multidisciplinary approach. (Staff Member 1)

This collaborative approach was valued with one student commenting:

Yeah but it was good to get everyone's input. I found that more real life as well; especially when you try developing a care plan to get the best care for your patient-having all the different services there together to work out the best course of action. I thought that was really good. (Student 3 )

While students had some understanding of the role of other disciplines, this was not fully appreciated until they experienced their peer's input into the care planning of the patient.

I knew about it but after doing this you realize how important everyone's input is. Like I know the other services were out there but I didn't realize the extent to which they could all actually help and impact on the care of the patient. (Student 3)

One student commented specifically on the input of nutrition and dietetics:

It makes you realize how important the dietician's input is, especially with someone who has weight or eating issues because there are so many other options out there. Like you can increase the calories in the food, they don't necessarily have to eat more, you can just give them a higher calorie diet to meet their nutritional requirements 
11

Collaboration in the Virtual World of

Second Life

Davis, Hercelinskyj, \& Jackson

Journal of Research in Interprofessional Practice and Education

Vol. 6.2

2016 and stabilize their weight and that sort of thing. Also, they can give you lots of tips as well, recommendations and that sort of thing. (Student 1)

This student also hoped that the dietetics student might have learnt something from her input, commenting, "I think they might have learnt a little more from the nursing side of things too" (Student 1).

Real life clinical placements do not always expose students to interprofessional collaboration and many are unaware of the role of other healthcare workers. This project exposed students to the role of other disciplines and went some way to exposing them to the skills necessary for effective collaboration.

\section{Discussion}

Virtual worlds such as Second Life are increasingly utilized in the education of healthcare professionals. While a number of studies have demonstrated that simulation improves knowledge and student confidence [35,36], evidence is lacking on whether this knowledge and confidence translates to real life clinical practice or whether virtual worlds offer any particular advantage over other simulation methods [33]. Regardless, learning and teaching strategies are burgeoning in this area as academics respond to challenges in the education of healthcare professionals and search for innovative ways to improve the student experience. The evidence lag reflects the relative newness of this technology, and we look forward to more robust research informing the arena in the future. While our study is small, it contributes to the body of work on the use of simulation in virtual worlds in healthcare education and also presents an innovative approach to interprofessional learning in the healthcare professions more broadly.

This project was aided by the fact that Institution A already had an established virtual hospital in Second Life. Otherwise set-up costs would have been prohibitive. Setup costs, along with maintenance of the learning space, have been identified as pitfalls of using virtual worlds such as Second Life as a teaching and learning space [37]. Other costs associated with the development of this initiative related to staff member's time, though we would argue that investing in exploring innovations and potential for interprofessional learning is money well spent. While some have suggested that the learning curve for students navigating virtual worlds such as Second Life is steep [38], this did not seem to be an issue for those participating in our pilot project. This may reflect greater exposure of students to digital media in general and the development of transferrable skills or improvement in the tools and processes for navigation in Second Life itself. Participants in our study found the environment and artefacts to be realistic and this contributed to their engagement with the scenario. Minocha and Mount, in an education project focusing on realism and immersion in virtual worlds, suggest that the two concepts (realism and immersion) do not necessarily go hand in hand [39]. Immersion is a complex concept according to these authors and may be related more to engagement with a learning and teaching strategy than to any sense of presence in the environment. They suggest that the learning activity itself is the most important factor impacting student engagement. Our pilot 
12

Collaboration in the Virtual World of

Second Life

Davis, Hercelinskyj, \& Jackson

Journal of Research in Interprofessional Practice and Education

Vol. 6.2

2016 project presented students with a variety of opportunities depending on the curricula of the particular discipline-a new practice context for some (students of nutrition and dietetics) and a more familiar one for others (nurses, enrolled nurses, and pharmacy students). All participants reported that the experience contributed to the development of their discipline specific knowledge and skills. An interesting finding related to the sense of autonomy that at least one student experienced in this learning milieu. Student midwives evaluating the Virtual Birth Centre Project in Second Life [40] similarly valued the opportunity to engage in role play situations free from the surveillance that accompanies real life clinical placements or classroom role plays. This is an area that is worthy of further exploration.

The primary aim of the project was to promote interprofessional collaboration, and we consider that the project allowed students to take some tentative first steps in this direction. Students participating in this pilot project became more aware of the role of the other healthcare professionals involved, but were not given the opportunity to build the depth of relationship required to effectively work together in multidisciplinary teams. Nonetheless, this awareness is the foundation on which effective collaborative teams can be built. Profession-specific training (the silo model) is one of the barriers to multidisciplinary teamwork identified by Wilson and Pirrie [41]. Along with a commitment to a multidisciplinary approach, these authors identify training in an interprofessional approach as key to successful interprofessional collaboration. This includes developing an understanding of each other's roles and working to a common vision or purpose.

The Institute of Medicine put forward a conceptual framework for measuring the impact of IPE [42]. The framework uses a learning continuum and describes the importance of interprofessional education as increasing from foundational to graduate learning through to continuing professional development. This approach acknowledges the need of learners to develop their professional identity at the foundational level and also the important role of the workplace in developing collaborative healthcare practices. It draws on Kirkpatrick's [42] work in describing a typology of learning outcomes that begins at the learner's reaction moving to modification of attitudes and perceptions, knowledge and skills, behavioural change, organizational practice, and finally to patient outcomes. Drawing on the conceptual framework and outcomes typology, it would be reasonable to suggest that programs focusing on foundational learning could focus on at least the first three outcomes in the typology; reaction, attitudes/perceptions, and knowledge and skills. Our strategy may have contributed to the first two outcomes in this typology: the reaction, attitudes, and perceptions of students toward interprofessional practice though a more directed evaluation (with specific outcomes measures) would be required to ascertain this. On reflection we feel we could have done more to develop the skills of students in this approach before exposing them to the scenario. This might include some preliminary work on collaboration, including exploration of roles, professional boundaries, and communication skills (e.g., negotiation and conflict resolution skills). This may have prepared students to more comfortably enter into a community of diverse practitioners, enact their discipline-specific understandings and role, 
Collaboration in the Virtual World of Second Life

Davis, Hercelinskyj, \& Jackson
Journal of Research in Interprofessional Practice and Education

Vol. 6.2

2016

\section{Journal of Research in Interprofessional Practice and Education}

connect confidently with other disciplines, and to share their beliefs, values, and knowledge about their practice $[43,44]$.

A number of institutional issues continue to act as barriers to the large-scale introduction of IPE programs such as this, and these have been well documented. In an Australia-wide survey, the Interprofessional Curriculum Renewal Consortium identified enablers and barriers for IPE that included: curriculum and course design, leadership, stakeholder/industry links, funding and support, cross-disciplinary collaboration, and the dispersal of programs across various schools and geographic locations [45]. Our project makes a useful contribution in relation to the latter. It demonstrates that it is possible to engage participants from various disciplines, institutions, and geographic locations in simulations using virtual environments.

While collaboration across institutions and degree programs presents a number of challenges for academics designing learning and teaching strategies for their students, the changing context of healthcare, and the imperative to better prepare students to work in multidisciplinary teams, means that we must commit to focusing on interprofessional collaboration at the earliest opportunity.

\section{Limitations}

This is a small study reporting on the evaluation of a novel project. A self-selected group of students and staff members were involved and this introduces the potential for selection bias. The experiences of these participants cannot be generalized to the wider university community. Future work of this kind should focus on introducing and evaluating the innovation in a broader cross-section of the university community. In addition, due to budget limitations, members of the project steering committee who have a vested interest in the project conducted the evaluation. Ideally, researchers who are external to the project and are therefore more objective in relation to the outcomes should undertake this.

\section{Conclusion}

The healthcare context is demanding greater interprofessional collaboration in an increasingly patient-centred approach to care, and yet most healthcare degree programs provide students with little opportunity to develop the knowledge and skills necessary for such an approach. Many institutions (including our own) offer a variety of healthcare related degree programs, but continue to educate these students in isolation from each other. This article presented an innovative project that represents the first steps in addressing this problem. The evaluation of this pilot project demonstrated that participants were able to use the technologies associated with Second Life after a relatively brief orientation, and that the learning and teaching strategies developed were engaging and useful. The main aim of the project was to promote interprofessional collaboration and while the project provided students with an opportunity to learn more about the role of other healthcare professionals and their contribution to patient care, the project will require some development before it achieves this aim in full. 
Collaboration in the Virtual World of Second Life

Davis, Hercelinskyj, \& Jackson
Journal of Research in Interprofessional Practice and Education

Vol. 6.2

2016

\section{References}

1. Australian Health Ministers. (2009). Fourth national mental health plan-An agenda for collaborative government action in mental health 2009-2014. ACT Australia: Australian Commonwealth Government.

2. Cant, R., \& Cooper, S. (2010). Simulation-based learning in nurse education: systematic review. Journal of Advanced Nursing, 66(1), 3-15.

3. Alinier, G., Harwood, C., Harwood, P., Montague, S., Huish, E., Ruparelia, K., \& Antuofermo, M. (2014). Immersive clinical simulation in undergraduate health care interprofessional education: Knowledge and perceptions. Clinical Simulation in Nursing, 10(4), e205-e216.

4. Belanger, E., \& Rodriguez, C. (2008). More than the sum of its parts? A qualitative research synthesis on multi-disciplinary primary care teams. Journal of Interprofessional Care, 22(6), 587-597.

5. World Health Organization. (2010). Framework for action on interprofessional education \& collaborative practice. Geneva, Switzerland: World Health Organization.

6. Centre for Advancement of Interprofessional Education. (2002). Defining IPE: 2015. URL: http://caipe.org.uk/about-us/defining-ipe/ [July 30, 2015]

7. Canadian Interprofessional Health Collaborative. (2010). A national interprofessional competency framework. Vancouver, BC: University of British Columbia.

8. Dennis, S. (2006). The tip of the iceberg. In C. Gamble \& G. Brennan (Ed.), Working with serious mental illness. A manual for clinical practice (pp. 389-398). Edinburgh, UK: Elsevier.

9. Newton, C., Wood, V., \& Nasmith, L. (2012). Building capacity for interprofessional practice. The Clinical Teacher, 9(2), 94-98.

10. MacDonald, C.J., Stodel, E.J., \& Chambers, L.W. (2008). An online interprofessional learning resource for physicians, pharmacists, nurse practitioners, and nurses in long-term care: Benefits, barriers, and lessons learned. Informatics for Health \& Social Care, 33(1), 21-38.

11. Reeves, S., Zwarenstein, M., Goldman, J., Barr, H., Hammick, M., \& Koppel, I. (2009). Interprofessional education: Effects on professional practice and health care outcomes, 1(Art. No. CD002213). Cochrane Database of Systematic Reviews.

12. Priest, H.M., Roberts, P., Dent, H., Blincoe, C., Lawton, D., \& Armstrong, C. (2008). Interprofessional education and working in mental health: In search of the evidence base. Journal of Nursing Management, 16(4), 474-485.

13. Ker, J., Mole, L., \& Bradley, P. (2003). Early introduction to interprofessional learning: A simulated ward environment. Medical Education, 37(3), 248-255.

14. Hall, P., \& Weaver, L. (2001). Interdisciplinary education and teamwork: A long and winding road. Medical Education, 35(9), 867-875.

15. Devonshire, L., \& Wozniak, H. (2006). Working together: Developing eLearning activities to promote interprofessional learning. Synergy, 23, 25-27.

16. Ateah, C.A., Snow, W., Wener, P., MacDonald, L., Metge, C., Davis, P., Fricke, M., Ludwig, S., \& Anderson, J. (2011). Stereotyping as a barrier to collaboration: Does interprofessional education make a difference? Nurse Education Today, 31(2), 208-213.

17. Heinrichs, W., Youngblood, P., Harter, P., \& Dev, P. (2008). Simulation for team training and assessment: Case studies of online training with virtual worlds. World Journal of Surgery, 32(Special Issue), 161-170.

18. Morey, J., Simon, R., Jay, G., Wears, R., Salisbury, M., Dukes, K., \& Bers, S. (2002). Error reduction and performance improvement in the emergency department through formal teamwork training: Evaluation results of the MedTeams project. Health Services Research, 37(6), 1553-1581.

19. Thistlethwaite, J. (2012). Interprofessional education: A review of context, learning and the research agenda. Medical Education, 46(1), 58-70.

20. Lapkin, S., Levett-Jones, T., \& Gilligan, C. (2012). A cross-sectional survey examining the extent to which interprofessional education is used to teach nursing, pharmacy and medical students in Australian and New Zealand Universities. Journal of Interprofessional Care, 26(5), 390-396.

21. Tourse, R., Mooney, J., Shindul-Rothschild, J., Prince, J., Pulcini, J., Platt, S., \& Savransky, H. (2008). The university/community partnership: Transdisciplinary course development. Journal of Interprofessional Care, 22(5), 461-474.

22. Wilhelmsson, M., Ponzer, S., Dahlgren L., Timpka, T., \& Faresjo T. (2011). Are female students in general and nursing students more ready for teamwork and interprofessional collaboration in healthcare? BMC Medical Education, 11(1), 15.

23. Bridges, D., Davidson, R., Soule Odegard, P., Maki, I., \& Tomowiak, J. (2011). Interprofessional collaboration: Three best practice models of interprofessional education. Medical Education Online, 16(6035). URL: http://www.ncbi.nlm.nih.gov/pubmed/21519399 [July 30, 2015]. 
15

Collaboration in the Virtual World of Second Life

Davis, Hercelinskyj, \& Jackson
Journal of Research in Interprofessional Practice and Education

Vol. 6.2

2016
24. Hercelinskyj, J., \& McEwan, B. (2011). The Charles Darwin University Hospital: Creating an authentic virtual learning environment for undergraduate nursing students. In M. Keppell., K. Souter, \& M. Riddle (Ed.), Physical and virtual learning spaces in higher education (pp. 219-241). Hershey, PA: IGI Global.

25. Clapper, T.C. (2010). Beyond Knowles: What those conducting simulation need to know about adult learning theory. Clinical Simulation in Nursing, 6(1), e7-e14.

26. Herrington, J. (2006). Authentic e-learning in higher education: Design principles for authentic learning environments and tasks. In T. Reeves, \& S. Yamashita (Eds.), Proceedings of e-learn: World conference on e-learning in corporate, government, healthcare, and higher education 2006 (pp. 3164-3173). Chesapeake, VA: Association for the Advancement of Computing in Education (AACE).

27. Johnson, L., Levine, A., Smith, R., Smythe, T., \& Stone, S. (2009). The Horizon Report: 2009 AustraliaNew Zealand Edition. Austin, TX: The New Media Consortium.

28. Donovan, T., Hutchison, T., \& Kelly A. (2003). Using simulated patients in a multiprofessional communications skills programme: Reflections from the programme facilitators. European Journal of Cancer Care, 12, 123-128.

29. Decker, S., Sportsman, S., Puetz, L., \& Billings, L. (2008). The evolution of simulation and its contribution to competency. Journal of Continuing Education in Nursing, 39(2), 74-80.

30. Maran, N., \& Glavin, R. (2003). Low-to-high-fidelity simulation - A continuum of medical education? Medical Education, 37, 22-28.

31. Ellis, D., Crofts, J., Hunt, L., Read, M., Fox, R., \& Mark, J. (2008). Hospital, simulation center, and teamwork training for eclampsia management: A randomized controlled trial. Americal Journal of Obstetics and Gynecology, 111(3), 723-731.

32. Stewart, S., \& Davis, D. (2012). On the MUVE or in decline: Reflecting on the sustainability of the Virtual Birth Centre developed in Second Life. Australasian Journal of Educational Technology, 28(3), 480-503.

33. De Gagne, J., Oh, J., Kang, J., Vordestrasse, A., \& Johnson, C. (2013). Virtual worlds in nursing education: A synthesis of the literature. Journal of Nursing Education, 52(7), 391-396.

34. Sandelowski, M. (2000). Focus on research methods-whatever happened to qualitative description? Research in Nursing and Health, 23(4), 334-340.

35. Burns, H., O’Donnell, J., \& Artman, J. (2010). Highfidelity simulation in teaching problem solving to 1st-year nursing students: A novel use of the nursing process. Clinical Simulation in Nursing, 6(3), e87-e95.

36. Jeffries, P., \& Rizzolo, M. (2006). Designing and implementing models for the innovative use of simulation to teach nursing care of ill adults and children: A national, multi-site, multi-method study. New York, NY: National League for Nursing.

37. Willems, J. (2009). Different spaces but same places: Possibilities, pitfalls and persistent practices in Second Life. In Same places, different spaces. Proceedings ascilite Auckland 2009. URL: http://www.ascilite.org.au/conferences/auckland09/procs/willems.pdf [March 20, 2016].

38. Inman, C., Wright, V., \& Hartman, J. (2010). Use of second life in K-12 and higher education: A review of research. Journal of Interactive Online learning, 9(1), 44-63.

39. Minocha, S., \& Mount, N. (2009). Design of learning spaces in 3D multi-user virtual environments. Proceedings of the Research Learning in Virtual Environments International Conference, pp. 228-235.

40. Winter, M. (2010). Second life education in New Zealand. Evaluation research. Final report. URL: http://en.wikieducator.org/images/1/13/Slenz-final-report-_milestone-2_-080310cca.pdf [July 30, 2015].

41. Wilson, V., \& Pirrie, A. (2000). Multidisciplinary teamworking: Beyond the barriers? A review of the issues. Edinburgh, UK: SCRE.

42. IOM (Institute of Medicine). (2015). Measuring the impact of interprofessional education on collaborative practice and patient outcomes. Washington, DC: The National Academies Press.

43. Gherardi, S. (2005). Organizational knolwedge. The texture of workplace learning. Hoboken, NJ: Wiley.

44. Lee, M. (2009). How can 3d virtual worlds be used to support collaborative learing? Journal of elearning and Knowledge Society, 5(1), 149-158.

45. The Interprofessional Curriculum Renewal Consortium, Australia. (2013). Curriculum renewal for interprofessional education in health. Sydney, AUS: Centre for Research in Learning and Change, University of Technology, Sydney. 